\title{
Unaltered imprinting establishment of key imprinted genes in mouse oocytes after in vitro follicle culture under variable follicle-stimulating hormone exposure
}

\author{
ELLEN ANCKAERT ${ }^{*}{ }^{* 1}$, TOM ADRIAENSSENS ${ }^{1}$, SERGIO ROMERO ${ }^{1}$, SARAH DREMIER ${ }^{2}$ and JOHAN SMITZ ${ }^{1}$ \\ ${ }^{1}$ Follicle Biology Laboratory, Universitair Ziekenhuis Brussel, Brussels and ${ }^{2}$ Cloning department, BioVallée, Gosselies, Belgium
}

\begin{abstract}
Imprinted genes are differentially methylated during gametogenesis to allow parental-specific monoallelic expression of genes. During mouse oogenesis, DNA methylation at imprinted genes is established during the transition from primordial to antral follicle stages. Studies in human and mouse suggest aberrant imprinting in oocytes following in vitro maturation and after superovulation with high doses of gonadotrophines. The exact mechanisms leading to aberrant imprinting are unknown. We examined the methylation status of differentially methylated regions of key imprinted genes (by bisulphite sequencing) in mouse metaphase Il oocytes, grown in a long-term pre-antral follicle culture system and matured in vitro, in the presence of a physiological (10 IU/L) and a high (100 IU/L) recombinant FSH dose. Our results showed a normal DNA methylation at the studied regulatory sequences of Snrpn, Igf2rand H19, demonstrating that 1) prolonged culture and in vitro maturation do not per se modify the establishment of imprinting in oocytes and 2) supraphysiological FSH doses do not induce aberrant DNA methylation at the studied regulatory sequences in this system.
\end{abstract}

KEYWORDS: DNA methylation, follicle culture, genome imprinting, in vitro maturation, FSH, mouse oocyte

\section{Introduction}

Genomic imprinting is a phenomenon leading to sex-specific monoallelic expression of genes (Surani et al., 1984; Reik and Walter, 2001). Imprinting explains why both maternal and paternal genomes are required in normal development (McGrath and Solter, 1984). Imprinted genes play important roles in embryo development and growth, placental differentiation and neurobehavioural processes (reviewed by Isles and Holland, 2005; Fowden et al., 2006; Smith et al., 2006). Furthermore, aberrant imprinting is linked to human diseases like BeckwithWiedemann, Prader-Willi and Angelman syndromes (reviewed by Paulsen and Ferguson-Smith, 2001).

DNA methylation is considered an important epigenetic mechanism for differentially marking the parental alleles of imprinted genes, which is involved in sex-specific gene expression (reviewed by Li et al., 2002). DNA methylation occurs at cytosine residues, mainly within $\mathrm{CpG}$ dinucleotides, and is catalyzed by a family of DNA methyltransferases (Bestor et al., 2000). For imprinted genes, the gene itself or nearby regulatory sequences are differentially methylated in the parental alleles: these regions are the so-called differentially methylated regions (DMR). Imprints are erased in primordial germ cells (Hajkova et al., 2002; Lee et al., 2002) and reset during gametogenesis in a sex-specific manner; the latter is called primary imprinting. In mouse, primary imprinting is established at a specific time for each gene during postnatal oocyte growth (Bao et al., 2000; Obata and Kono, 2002). DNA methylation occurs asynchronously at different imprinted genes, while oocytes are arrested at prophase I during the transition from primordial to antral follicle stages (Lucifero et al., 2002 and 2004; Hiura et al., 2006). This acquisition of DNA methylation during oogenesis correlates with an increase in oocyte diameter (Lucifero et al., 2004; Hiura et al., 2006).

Several studies have linked assisted reproductive technology (ART) to aberrant imprinting. In vitro culture of pre-implantation embryos was associated with aberrant expression and/or DNA methylation of imprinted genes in different species (reviewed by Khosla et al., 2001). Notably, the addition of serum to embryo

Abbreviations used in this paper: ART, assisted reproductive technology; DMR, differentially methylated region; FSH, follicle-stimulating hormone.

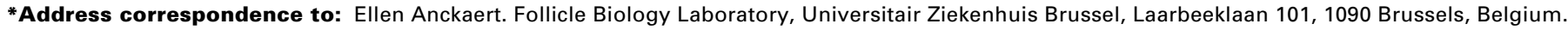
Fax.+32-2-4775060. e-mail: Ellen.Anckaert@uzbrussel.be
} 
culture medium in mouse is associated with aberrant imprinting (Khosla et al., 2001), although the exact causative factor in serum remains unknown.

Recent studies suggest that manipulation of oocytes is also associated with aberrant imprinting. A study in human suggested aberrant DNA methylation at the imprinted $\mathrm{H} 19$ gene in oocytes following in vitro maturation (IVM) (Borghol et al., 2006) and prolonged IVM of mouse oocytes was associated with a loss of DNA methylation at Peg1 (Imamura et al., 2005). Another study reported aberrant DNA methylation at imprinted genes in oocytes after superovulation with high doses of gonadotrophins in mouse and human (Sato et al., 2007).

Several studies have suggested an increased incidence in rare human imprinting disorders in children conceived after ART (Cox et al., 2002; DeBaun et al., 2003; Gicquel et al., 2003; Maher et al., 2003; Orstavik et al., 2003). Methylation analysis in the affected ART-children revealed a hypomethylation of the maternal allele at the imprinted Snrpn and Konq1ot1 locus, which are involved in respectively Angelman and BeckwithWiedemann syndrome (DeBaun et al., 2003; Gicquel et al., 2003; Maher et al., 2003; Orstavik et al., 2003). The exact mechanisms that lead to aberrant imprinting of these maternal alleles after ART are unknown. Therefore, more research is needed to determine causative factors for aberrant imprinting in ART protocols.

Follicle culture and IVM are new alternative techniques progressively being introduced into the assisted reproductive laboratories to obtain large numbers of oocytes for cloning or to avoid using any hormones in well-defined patient groups (Ohkoshi et al., 2003; Suikkari and Soderstrom-Anttila, 2007; Holzer et al., 2007). However, only very limited information is currently available on the effects of IVM on DNA methylation of imprinted genes in oocytes. A mouse follicle culture system allows the growth of massive amounts of oocytes from early pre-antral follicles up to fertilisable metaphase II (MII) oocytes under fully defined conditions during a 13-day culture period (Cortvrindt and Smitz, 2002). The first aim of the study was to compare the DNA methylation status at regulatory sequences of 4 imprinted genes in mouse MII oocytes obtained after prolonged follicle culture and in vitro oocyte maturation with in vivo grown oocytes after conventional superovulation (Cortvrindt and Smitz, 2002).

Studies on the effects of superovulation on DNA methylation have shown conflicting results. One study reported aberrant DNA methylation at the $\mathrm{H} 19$ gene in oocytes after superovulation with high doses of gonadotrophins in mouse and human (Sato et al., 2007). However, two recent studies have shown that superovulation may induce aberrant expression of imprinted genes in blastocysts $(H 19)$ or 9.5 dpc placentae $(H 19$ and Snrpn) with normal DNA methylation patterns at regulatory sequences of the studied imprinted genes (Fauque et al., 2007; Fortier et al., 2008). The latter studies suggest that superovulation interferes with the maintenance of imprinting after fertilization, but that DNA methylation at regions known to be important for imprint establishment in oocytes is not altered by superovulation. Therefore, the second aim of our study was to assess the influence of high doses of recombinant $\mathrm{FSH}(\mathrm{r}-\mathrm{FSH})$ in the follicle culture system on DNA methylation of 3 imprinted genes in MII oocytes.

We analyzed differentially methylated regions of small nuclear ribonucleoprotein N (Snrpn), insulin-like growth factor 2 receptor (Igf2r), paternally expressed gene $3(P e g 3)$ and $H 19$ by the bisulphite sequencing technique. In mouse oocytes, the DMRs of Snrpn, Igf2r and Peg3 acquire DNA methylation during oogenesis in the post-natal growth phase (Lucifero et al., 2004). At $H 19$, DNA methylation is acquired in the male germ line (Davis et al., 1999 and 2000). We chose these genes because methylation dynamics during oogenesis have been extensively characterized for these genes, and because of their biological significance. The analyzed sequence for Snrpn corresponds to the human SNRPN locus, in which abnormal methylation was related to Prader-Willi and Angelman syndromes (Bielinska et al., 2000). The Igf2rgene plays an important role in embryo development and fetal growth, and abnormal lgf2rimprinting was linked to large offspring syndrome after in vitro embryo culture in sheep (Young et al.; 2001). Abnormal methylation at $H 19$ was linked to Beckwith-Wiedemann (DeBaun et al., 2003). Moreover, a gain of methylation at $H 19$ in oocytes

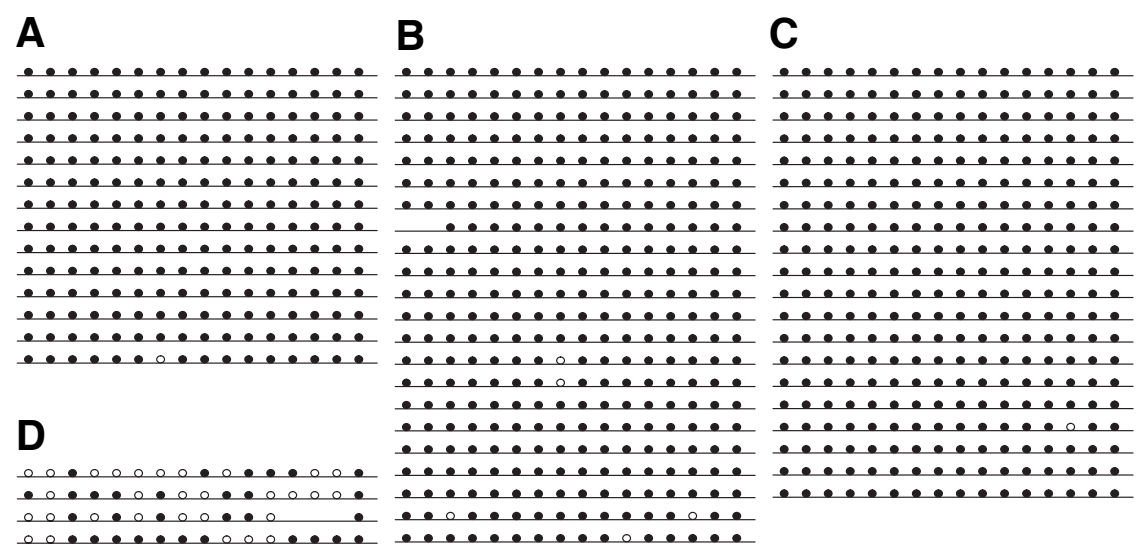

Fig. 1. DNA methylation of Snrpn (DMR1) (A) in in vivo grown and PMSG/hCG superovulated MIl oocytes; (B) in MIl oocytes after prolonged follicle culture and in vitro oocyte maturation in the presence of $10 \mathrm{IU} /$ $\mathrm{L} \mathrm{r-FSH;} \mathrm{(C)} \mathrm{in} \mathrm{MIl} \mathrm{oocytes} \mathrm{after} \mathrm{prolonged} \mathrm{follicle}$ culture and in vitro oocyte maturation in the presence of $100 \mathrm{IU} / \mathrm{L} \mathrm{r-FSH}$ and (D) in oocytes from early preantral follicles from 13-14 day-old mice. Each line represents an individual allele and each circle represents a CPG site within the DMR analyzed. Filled circles, methylated cytosines; open circles, unmethylated cytosines; missing circles, CpG sites whose methylation status could not be determined.

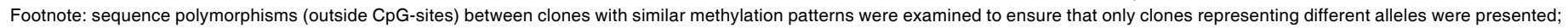

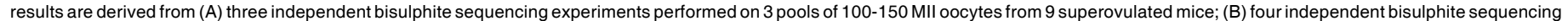

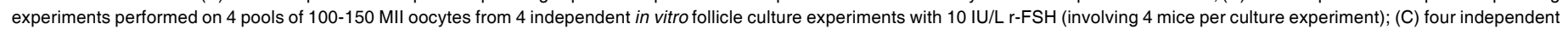

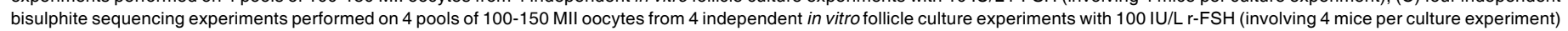
and (D) one bisulphite sequencing experiment performed on one pool of 100 oocytes from early pre-antral follicles (derived from four 13-14 day-old mice). 
has been described after IVM in human and after superovulation in human and mouse (Borghol et al., 2006; Sato et al., 2007).

\section{Results}

\section{DNA methylation patterns at imprinted genes in cumulus cells}

PCR amplification on bisulphite-treated DNA is prone to PCR bias, most commonly resulting in preferential amplification of DNA stands that are unmethylated at CpG-sites (Warnecke et al., 1997). Therefore, the DNA methylation analysis was validated on pools of approximately 100-200 cumulus cells.

One or two PCR amplifications were performed for each gene and 8 clones were sequenced per PCR reaction. For all genes, both maternal (>95\% methylation at CpG-sites for Snrpn, Peg3 and $\operatorname{lgf} 2 \mathrm{r}$, and $0 \%$ methylation for $\mathrm{H} 19)$ and paternal alleles $(0 \%$ methylation for Snrpn, Peg3 and Igf2r, and 100\% methylation for H19) could be amplified in cumulus cells (results not shown).

\section{DNA methylation patterns at imprinted genes in oocytes}

The bisulphite sequencing technique leads to an important loss of DNA (>85\%) and subsequently, to the amplification of only a limited number of different alleles when performed on small numbers of cells (Grunau et al., 2001). Therefore, sequence polymorphisms (outside CpG-sites) between clones with similar methylation patterns were examined to ensure that only different alleles were included in the results for the oocytes. In total, approximately 672 clones were examined (192 for the superovulated MII oocytes; 448 for the MII oocytes after follicle culture and 32 for the oocytes from early pre-antral follicles), but only clones representing different alleles are shown in the results. Three up to eight different alleles could be obtained per gene for each oocyte pool.

Metaphase II oocytes from superovulated adult animals. The DNA methylation pattern of the DMRs of Snrpn, Peg3, Igf2r and H19 has been described previously for superovulated metaphase II oocytes in adult female mice (Lucifero et al., 2002). Results of the DNA methylation analysis of DMRs of Snrpn, Peg3, Igf2rand H19 in our study are presented in Figs. 1-4 (A). All clones showed the previously described DNA methylation pattern. As expected, H19 was found to be unmethylated in MII oocytes and this also served as a control to exclude the presence of somatic cell contamination (paternal alleles display a fully methylated pattern at CpG-sites).
For Snrpn, Peg3 and Igf2r, the percentage of methylation at CpGsites was close to $100 \%$ as expected: $99.6 \%, 98.7 \%$ and $100 \%$ respectively.

Metaphase II oocytes obtained after in vitro follicle culture and in vitro maturation in the presence of $10 \mathrm{IU} / \mathrm{L}$ r-FSH. Results of DNA methylation analysis of DMRs of Snrpn, Peg3, Igf2r and $\mathrm{H} 19$ are presented in Figs. 1-4 (B). H19 was unmethylated in MII oocytes (0.7\% methylation at potential methylation sites). For Snrpn, $\mathrm{Peg} 3$ and $\operatorname{lgf} 2 \mathrm{r}$, the percentage of methylation at CpG-sites was close to $100 \%$ as in the in vivo grown oocytes: $98.6 \%, 99.4 \%$ and $97.1 \%$ respectively.

Metaphase II oocytes obtained after in vitro follicle culture and in vitro maturation in the presence of $100 \mathrm{IU} / \mathrm{L}$ r-FSH. Results of DNA methylation analysis of DMRs of Snrpn, Igf2r and $\mathrm{H} 19$ are presented in Figs. 1,3 and 4 (C). H19 was unmethylated in MII oocytes (2.2\% methylation at potential methylation sites). For Snrpn and Igf2r, the percentage of methylation at CpG-sites was $99.7 \%$ and $98.6 \%$ respectively.

Statistical analysis of DNA methylation percentages at imprinted genes in MIl oocytes. For Snrpn, Igf2r and H19 no significant difference in DNA methylation percentage was noted between superovulated MII oocytes and MII oocytes after in vitro follicle culture in the presence of $10 \mathrm{IU} / \mathrm{L} \mathrm{r}$-FSH or in the presence of 100 IU/L r-FSH, nor between MII oocytes from both culture conditions (10 and $100 \mathrm{IU} / \mathrm{L}$ r-FSH).

Likewhise, no statistically different DNA methylation percentage was noted for Peg3 between superovulated MII oocytes and $\mathrm{MII}$ oocytes after follicle culture in the presence of $10 \mathrm{IU} / \mathrm{L} \mathrm{r}-\mathrm{FSH}$.

Oocytes from early pre-antral follicles in 13-14 day old mice. H19 was unmethylated ( $0 \%$ methylation at potential methylation sites), excluding the presence of somatic cell contamination (results not shown). Snrpn showed $50.8 \%$ methylation at potential methylation sites (Fig. 1D).

\section{Oocyte diameter, MII rate and developmental capacity of MII oocytes after in vitro follicle culture and in vitro maturation in the presence of 10 and $100 \mathrm{IU} / \mathrm{L} \mathrm{r-FSH}$}

The mean diameter of fully grown germinal vesicle-stage oocytes was significantly larger for in vivo grown oocytes than for oocytes derived from in vitro follicle culture (at day 12) in the presence of $10 \mathrm{IU} / \mathrm{L}$ or $100 \mathrm{IU} / \mathrm{L} \mathrm{r}-\mathrm{FSH}$ : mean (SD) oocyte

TABLE 1

\section{OOCYTE DIAMETER, MII RATE AND DEVELOPMENTAL CAPACITY OF OOCYTES}

\begin{tabular}{|c|c|c|c|c|c|c|c|c|}
\hline oocyte source & $\mathrm{n}$ follicles & $\begin{array}{c}\text { mean (SD) } \\
\text { oocyte diameter }(\mu \mathrm{M})^{1}\end{array}$ & $\begin{array}{l}\text { mean (SD) } \\
\text { MII rate }(\%)\end{array}$ & $\begin{array}{l}n \text { oocytes }^{2} \\
\text { fertilized }\end{array}$ & 2-cell/oocyte (\%) & blastocyst/2-cell (\%) & $\begin{array}{c}\mathrm{n} \text { transferred } \\
\text { blastocysts }\end{array}$ & newborn/transfer (\%) \\
\hline $\begin{array}{l}\text { In vitro follicle culture } \\
10 \mathrm{IU} / \mathrm{L} \text { r-FSH }\end{array}$ & 672 & $71.6(2.5)$ & $92(6.1)$ & 550 & 52.0 & 54.3 & 208 & 3.4 \\
\hline $\begin{array}{l}\text { In vitro follicle culture } \\
100 \mathrm{IU} / \mathrm{L} \mathrm{r}-\mathrm{FSH}\end{array}$ & 658 & $71.6(2.5)$ & $94(7.9)$ & 555 & 53.5 & 46.8 & - & - \\
\hline In vivo grown & 56 & $84.8(4.6)$ & - & 1013 & 89.0 & 48.5 & 199 & 10.0 \\
\hline
\end{tabular}

Obtained from in vitro follicle culture and IVM in the presence of 10 or $100 \mathrm{IU} / \mathrm{L} \mathrm{r-FSH}$ and of in vivo grown oocytes

${ }^{1}$ oocytes from antral follicles at day 12 (in vitro follicle culture) or from antral follicles of 25 day-old mice (in vivo grown)

${ }^{2}$ oocytes for fertilization experiments were obtained from other follicle cultures than those presented in the table for oocyte diameter and MII rate. 
diameter was respectively 84.8 (4.6) $\mu \mathrm{M}, 71.6$ (2.5) $\mu \mathrm{M}$ and 71.6 (2.5) $\mu \mathrm{M}$; $\mathrm{p}<0.0001$ for both comparisons (see Table 1). Mean oocyte diameters at day 12 were not significantly different for in vitro follicle culture and IVM between both r-FSH conditions.

Similarly, the mean MII rate was not significantly different between both r-FSH conditions: mean (SD) MII rate was 92 (6.1) $\%$ in the presence of $10 \mathrm{IU} / \mathrm{L} \mathrm{r-FSH}$ and 94 (7.9) \% in the presence of $100 \mathrm{IU} / \mathrm{L} \mathrm{r}-\mathrm{FSH}$.

Results on the developmental capacity of in vivo grown (and superovulated) MII oocytes and MII oocytes after in vitro follicle culture and IVM are presented in Table1. These data are not based on the follicle cultures used for the present study, but are laboratory data derived from multiple follicle cultures performed over the last 2 years. After fertilization, the 2-cell stage/oocyte rate was lower for MIl oocytes obtained from in vitro follicle culture in the presence of 10 or $100 \mathrm{IU} / \mathrm{L} \mathrm{r-FSH}$ than for in vivo grown and superovulated MII oocytes: respectively $52 \%, 53.5 \%$ and $89 \%$ (pvalues $<0.0001$ ), but the blastocyst/2-cell rate was similar in the 3 groups: respectively $54.3 \%, 46.8 \%$ and $48.5 \%(p>0.05)$. The newborn/blastocyst transfer rate was lower for MII oocytes after follicle culture in the presence of $10 \mathrm{IU} / \mathrm{L} \mathrm{r}-\mathrm{FSH}$ than for in vivo grown and superovulated MII oocytes: respectively $3.4 \%$ and $10.0 \%, p=0.01$. No blastocyst transfer experiments were performed for MIl oocytes derived from in vitro follicle culture in the presence of $100 \mathrm{IU} / \mathrm{L}$ r-FSH (the policy was to consider only physiological r-FSH doses for transfer experiments).

\section{Discussion}

In this study, we compared DNA methylation at DMRs of 4 imprinted genes in mouse MII oocytes after prolonged in vitro follicle culture and in vitro oocyte maturation with in vivo grown oocytes after PMSG/hCG superovulation. The mouse follicle culture system allows oocytes to be grown from early pre-antral follicles up to fertilisable MII oocytes in a reproducible way during a 13-day culture period (Cortvrindt and Smitz, 2002). Our results indicate that oocytes derived from this follicle culture system have a lower diameter than in vivo grown oocytes as described previously for other follicle culture systems (Eppig and O'Brien, 1998). MII rates are above $90 \%$ and healthy offspring can be obtained from these oocytes, although at a lower rate than from in vivo grown oocytes.

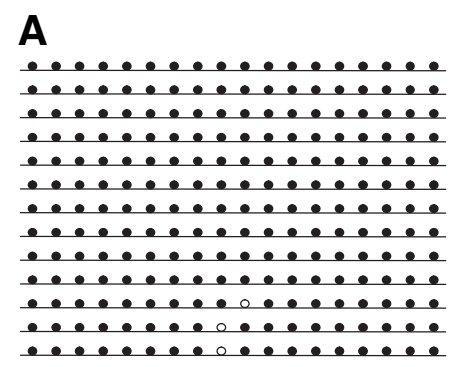

B

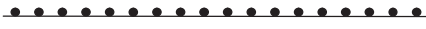
$\ldots \ldots \ldots \ldots . . \ldots$ $\ldots \ldots \ldots \ldots$ $\ldots \ldots \ldots \ldots$ $\ldots \ldots \ldots \ldots$

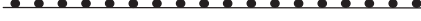
…......... $\ldots \ldots \ldots \ldots \ldots$ $\ldots \ldots \ldots \ldots \ldots \ldots$ $\bullet . . . . .0 . . . .$.
We found that DNA methylation at CpG-sites of DMRs of Snrpn, Peg3 and Igf2r in in vivo grown, PMSG/hCG superovulated oocytes was close to $100 \%$, as described previously for a different mouse strain (Lucifero et al., 2002). The methylation pattern in MII oocytes after prolonged in vitro follicle culture and oocyte maturation in the presence of $10 \mathrm{IU} / \mathrm{L} \mathrm{r}$-FSH was comparable to the superovulated MII oocytes. Previous studies have shown that in early pre-antral follicles, DNA methylation at DMRs of Snrpn, Peg3 and Igf2r is not fully established (Lucifero et al., 2004; Hiura et al., 2006). These findings were confirmed in our study for Snrpn in oocytes from early pre-antral follicles. Therefore, the correct DNA methylation pattern of Snrpn, Peg3and Igf2r in our study suggests that imprints for these 3 genes are correctly established under the actual in vitro follicle culture conditions and maintained in MII oocytes harvested at $18 \mathrm{~h}$ post hCG.

$A$ recent study in the same mouse strain suggested that prolonged IVM of oocytes in mouse ( $28 \mathrm{~h}$ of in vitro culture) leads to a loss of DNA methylation at the imprinted gene Peg1, suggesting that prolonged culture may result in a loss of previously acquired DNA methylation under certain culture conditions (Imamura et al., 2005). However, 28h of in vitro maturation is excessively long, considering the fact that at $16 \mathrm{~h}$ already, a maximum proportion of oocytes reach maturation, and that at $21 \mathrm{~h}$ post hCG aging effects are visible on the spindle apparatus (Segers et al., 2008).

The DNA methylation pattern at CpG-sites for $\mathrm{H} 19$ was $0 \%$ in the in vivo grown superovulated oocytes as described previously (Lucifero et al., 2002). Similarly, $0.7 \%$ methylation was found for $\mathrm{H} 19$ in MIl oocytes obtained with the follicle culture system in the presence of $10 \mathrm{IU} / \mathrm{L} \mathrm{r}-\mathrm{FSH}$. The imprinted gene $\mathrm{H} 19$ is not methylated during oogenesis, but was used in this study for two reasons: first, a non-methylated pattern at CpG-sites excluded the presence of cumulus cell contamination in the analyzed oocyte pools; second, hypermethylation at $H 19$ has been described in oocytes after IVM in human (Borghol et al., 2006) and

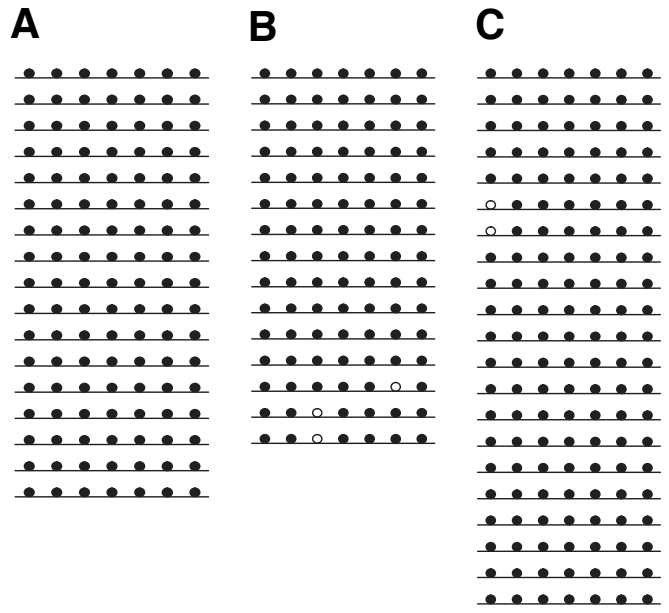

Fig. 2 (Left). DNA methylation of Peg3 (promoter and exon 1 region), (A) in in vivo grown and PMSG/hCG superovulated MII oocytes, and (B) in MIl oocytes after prolonged follicle culture and in vitro oocyte maturation in the presence of $10 \mathrm{IU} / \mathrm{L}$ r-FSH. For details, see Fig. 1 and its footnote.

Fig. 3 (Right). DNA methylation of Igf2r (DMR2), (A) in in vivo grown and PMSG/hCG superovulated MIl oocytes; (B) in MIl oocytes after prolonged follicle culture and in vitro oocyte maturation in the presence of $10 \mathrm{IU} / \mathrm{L} \mathrm{r-FSH}$ and $(\mathbf{C})$ in MIl oocytes after prolonged follicle culture and in vitro oocyte maturation in the presence of $100 \mathrm{IU} / \mathrm{L}$ r-FSH. For details, see Fig. 1 and its footnote. 
after gonadotrophin superovulation with high doses in human and mouse (Sato et al., 2007), suggesting that $H 19$ is susceptible to aberrant methylation in oocytes after in vitro culture or superovulation. The H19 CTCF1-2 region was recently shown to be particularly susceptible to aberrant methylation after IVF and embryo culture in mouse (Fauque et al., 2007). However, this H19 DMR did not show aberrant methylation after in vitro follicle culture and in vitro oocyte maturation in our study.

Our results are in contrast with a previous study, performed in the same mouse strain, suggesting that a 12-day in vitro follicle culture can lead to a loss of methylation at $\operatorname{lgf} 2 r$ DMR and a gain of methylation at $H 19 \mathrm{DMR}$ in fully grown germinal vesicle-stage oocytes (Kerjean et al., 2003). In the latter study, the culture medium used was $\alpha$-minimal essential medium as in our study, but $\mathrm{r}-\mathrm{FSH}$ was added in a concentration (100 IU/L) ten times higher than in this study (10 IU/L). Previous studies have established that the minimal effective dose of $\mathrm{r}-\mathrm{FSH}$ under the accompanying culture parameters is around $5 \mathrm{IU} / \mathrm{L}$. The dose of $10 \mathrm{IU} /$ $\mathrm{L}$ of $\mathrm{r}-\mathrm{FSH}$ could be considered physiological, while $100 \mathrm{IU} / \mathrm{L}$ exceeds the minimal needs by a factor of twenty (Adriaens et al., 2004). Our present results confirm that in vitrofollicle culture in the presence of $100 \mathrm{IU} / \mathrm{L}$ r-FSH does not result in larger oocyte diameters or in higher MII rates, nor in a higher blastocyst rate, when compared to the physiological r-FSH dose of $10 \mathrm{IU} / \mathrm{L}$. Studies on the effects of superovulation on DNA methylation have shown conflicting results. Superovulation with several doses of PMSG has been linked to aberrant DNA methylation of H19 in mouse oocytes (Sato et al., 2007). Two recent studies in mouse have shown that superovulation may induce aberrant expression of imprinted genes in blastocysts $(H 19)$ or 9.5 dpc placentae $(H 19$ and Snrpn), (Fauque et al., 2007; Fortier et al., 2008). However, DNA methylation patterns at the studied imprinted genes were not altered, suggesting that superovulation interferes with the main- tenance of imprinting after fertilization through mechanisms distinct from altered DNA methylation at the studied regulatory sequences. Therefore, we studied the effect of high doses of $r-$ $\mathrm{FSH}(100 \mathrm{IU} / \mathrm{L})$ in our follicle culture system on DNA methylation at regulatory sequences of Snrpn, Igf2r and H19 in MII oocytes. We found no alterations in DNA methylation levels, demonstrating that high doses of FSH do not induce aberrant DNA methylation at the studied regulatory sequences in oocytes.

Another difference between the present study and the study from Kerjean is that follicle culture was performed in small culture droplets under mineral oil in the latter (Kerjean et al., 2003). Perhaps prolonged culture in small medium droplets under mineral oil leads to an accumulation of toxic metabolic components such as ammonium in the culture medium. Ammonium has been linked with aberrant imprinting in in vitro pre-implantation embryo culture (Gardner and Lane, 2005). Follicles in their exponential growth phase have several thousands of metabolically active cells (Cortvrindt and Smitz, 1998) and might perhaps generate more or less toxic end products, depending on the hormonal composition of medium (FSH, insulin) and the oxygen exposure (Eppig et al., 2000).

There is growing concern that ART may lead to an increased incidence of rare imprinting disorders in children. Furthermore, methylation analysis of these affected ART-children points to a hypomethylation of the maternal allele at certain imprinted loci (DeBaun et al., 2003; Gicquel et al., 2003; Maher et al., 2003; Orstavik et al., 2003). Therefore, there is need for identifying factors possibly involved in aberrant imprinting in oocytes. We hypothesize that the mouse follicle culture model is a sensitive system that can be used in future experiments to study the influence of critical elements in culture conditions on imprinting establishment. The follicle culture bioassay might determine the critical stages of oocyte growth and maturation during which aberrant imprinting may be induced, by exposing follicles at different days of the culture, in a more reproducible and precise way than could be done by in vivo exposure. Ultimately, the model could be used for the optimalization of prolonged culture conditions of oocytes for clinical IVM.

In conclusion, MIl oocytes grown in a well-characterized long-term pre-antral follicle culture system, do show a normal DNA methylation at regulatory sequences of key imprinted genes in the presence of physiological and high dose $\mathrm{r}-\mathrm{FSH}$. The bisulphite sequencing technique is associated with a substantial loss of DNA, commonly resulting in amplification of only a few alleles. Therefore, it was decided to perform a high number of independent experiments and conclusions were based on a high number of different alleles.

To the best of our knowledge, this is the first study that shows that prolonged follicle culture and IVM can generate MII oocytes with normal DNA methylation
Fig. 4. DNA methylation of $\boldsymbol{H} 19$ (DMR containing the CTCF 1-2 region). ( $\boldsymbol{A}$ ) in in vivo grown and PMSG/hCG superovulated MII oocytes; (B) in MIl oocytes after prolonged follicle culture and in vitro oocyte maturation in the presence of $10 \mathrm{IU} / \mathrm{L} \mathrm{r-FSH}$ and $(\boldsymbol{C})$ in MII oocytes after prolonged follicle culture and in vitro oocyte maturation in the presence of $100 \mathrm{IU} / \mathrm{L} \mathrm{r-FSH}$. For details: see Fig. 1 and its footnote.
B

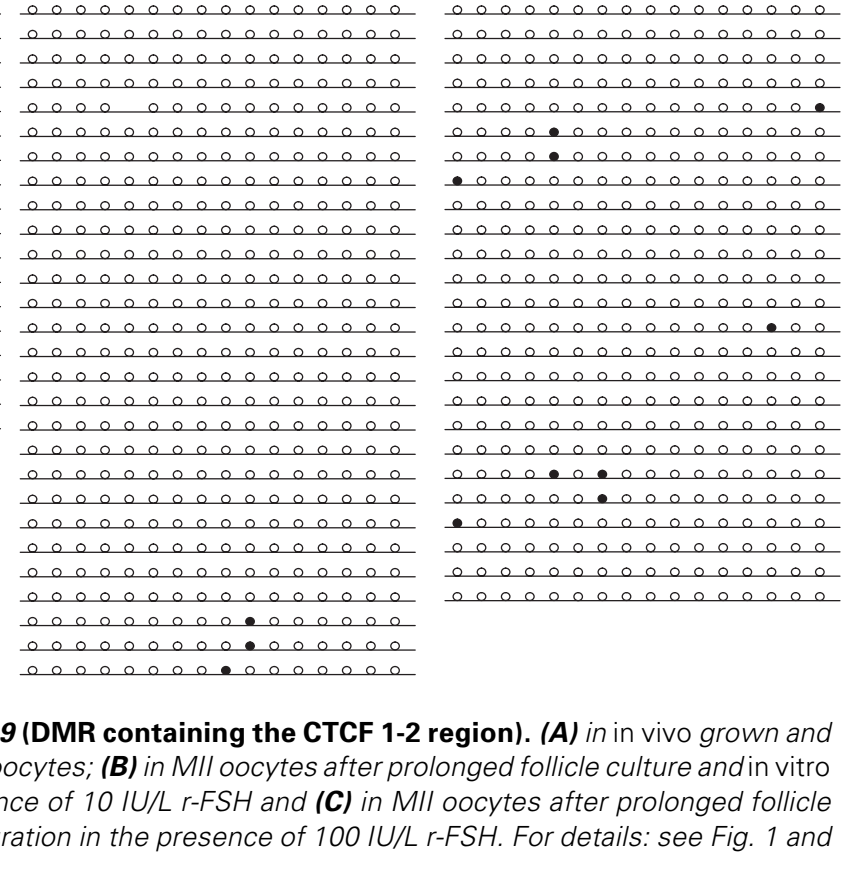


patterns at regulatory sequences of key imprinted genes even in the presence of high doses of FSH.

We speculate that deviations from normal concentrations of key components of culture medium and/or deviations from the biological time scales of critical growth and maturation processes might compromise normal establishment and/or maintenance of imprinting. Considering the low frequency of imprinting disorders after ART and the potential etiologies, it is extremely difficult to explore cause-effect relationships from clinical data. Precisely defined in vitro models are powerful tools for defining the edges of therapeutic interventionism.

\section{Materials and Methods}

\section{Oocyte and cumulus cell collection}

This study was performed with F1 mice (C57BL/6J x CBA/Ca; Harlan, The Netherlands), housed and bred according to the national standards for animal care, and approved by the Ethical Committee for animal experiments of the Vrije Universiteit Brussel (Project Nr. 01-395-1).

Adult 8-week old female mice were superovulated by intraperitoneal injection of $5 \mathrm{IU}$ of pregnant mares' serum gonadotrophin (PMSG, Intervet, Mechelen, Belgium), followed 48h later by intraperitoneal injection of $5 \mathrm{IU}$ human chorionic gonadotrophin (hCG, Intervet). Oocytes-cumulus cell complexes containing MII oocytes were removed from the oviducts $14 \mathrm{~h}$ after hCG injection and collected into L15 Leibovitz-glutamax medium supplemented with $10 \%$ Heat Inactivated Foetal Bovine Serum (HIA FBS), $100 \mu \mathrm{g} / \mathrm{ml}$ of streptomycin, and $100 \mathrm{IU} / \mathrm{ml}$ of penicillin (Invitrogen, Merelbeke, Belgium). Cumulus cells were removed from the superovulated MII oocytes with $1 \mathrm{mg} / \mathrm{mL}$ hyaluronidase (Roche Diagnostics, Brussels, Belgium). The MII oocytes used in the experiments were obtained from 9 superovulated mice. Per superovulated female, 30 to $45 \mathrm{MII}$ oocytes were obtained.

Metaphase II oocytes were obtained after in vitro follicle culture as described previously (Cortvrindt and Smitz, 2002). Briefly, early pre-antral follicles with a diameter between 100 and $130 \mu \mathrm{m}$ were mechanically isolated from the ovaries of 13-14-day-old F1 mice in L15 medium (Fig. 5). The follicle culture medium consisted of $\alpha$-minimal essential medium $(\alpha-$ MEM, Invitrogen) supplemented with $5 \%$ HIA FBS, $5 \mu \mathrm{g} / \mathrm{ml}$ insulin, $5 \mu \mathrm{g} / \mathrm{ml}$ transferrin and $5 \mathrm{ng} / \mathrm{ml}$ selenium (ITS, Sigma, Bornem, Belgium) and $10 \mathrm{IU} /$ $\mathrm{L}$ or $100 \mathrm{IU} / \mathrm{L}$ recombinant follicle-stimulating hormone $\left(\mathrm{r}-\mathrm{FSH}\right.$, Gonal- $\mathrm{F}^{\circledR}$, Serono, Benelux). Follicles were individually cultured in $75 \mu \mathrm{l}$ medium in $96-$ wells (Costar, Belgium) for a 12-day period to grow to antral follicles. Follicles were cultured in an incubator at $37^{\circ} \mathrm{C}, 100 \%$ humidity and $5 \% \mathrm{CO}_{2}$ in air. Exchanging part of the medium $(30 \mu \mathrm{l})$ was done on days 4,8 and 12 . At the end of the 12-day culture period, an ovulatory stimulus with $1.2 \mathrm{IU} /$ $\mathrm{ml}$ recombinant human chorionic gonadotrophin ( $\mathrm{r}-\mathrm{hCG}$, Ovitrelle, Serono,
Benelux) supplemented with $4 \mathrm{ng} / \mathrm{ml}$ recombinant epidermal growth factor ( $r$-EGF, Roche Diagnostics) was given. Oocyte-cumulus cell complexes containing MII oocytes were collected into L15 medium 18 hours after $r-$ hCG/r-EGF. The MIl oocytes used for the experiments were obtained from 8 independent repeat cultures ( 4 for the $10 \mathrm{lU} / \mathrm{L} \mathrm{r}$-FSH and 4 for the $100 \mathrm{IU} /$ $\mathrm{L} \mathrm{r}$-FSH condition) involving 4 mice per culture experiment.

Oocytes were washed free from somatic cells by transfer through three washes of $\mathrm{L} 15$ medium with a mouth-controlled glass pipette. One hundred to $150 \mathrm{MIl}$ oocytes per culture were pooled. One hundred oocytes from early pre-antral follicles (with a diameter between 100 and $130 \mu \mathrm{m}$ ) in ovaries of four 13-14-day-old F1 mice were collected as described previously (Lucifero et al., 2002) and pooled.

Special care was taken that no cumulus cells should contaminate the oocyte samples. Furthermore, $\mathrm{H} 19$ methylation analysis was performed to ensure the absence of cumulus cell contamination (fully methylated H19 strands suggest cumulus cell contamination) and none of the examined clones showed a methylated pattern.

Cumulus cells were collected separately (cumulus cells from $1 \mathrm{COC}$ complex per sample) to serve as somatic cell controls for validation of the bisulphite sequencing technique.

\section{DNA methylation analysis and PCR}

DNA was extracted from the oocyte pools (containing 100-150 oocytes per pool) using the QIAamp DNA Micro kit (Qiagen, Venlo, The Netherlands). Bisulphite treatment was performed with the EZDNA Methylation kit (Zymogen Research, Orange, CA, USA). DNA was eluted in $10 \mu \mathrm{L}$ of the kit's elution buffer, stored at $-80^{\circ} \mathrm{C}$ and used within 2 weeks for PCR. Nested PCR was performed for amplification of DMRs of the imprinted genes $\mathrm{H} 19$, Snrpn, Peg3 and Igf2r. For H19, Snrpn and Igf2r, PCR was performed on 3 (superovulation) or 8 (in vitro follicle culture conditions) independent samples of 100-150 MII oocytes with primers for bisulphite-treated DNA. For Peg3, PCR was performed on 3 (superovulation) or 4 (in vitro follicle culture in the presence of $10 \mathrm{IU} / \mathrm{L} \mathrm{r}-\mathrm{FSH}$ ) independent samples of 100-150 MII oocytes. Furthermore, one PCR was performed for Snrpn and H19 on the pool of 100 oocytes from early pre-antral follicles. Primer sequences for SnrpnDMR1, Igf2rDMR2, Peg3promoter and exon 1 region and H19DMR (containing the CTCF 1-2 region involved in imprinted expression of Igf2), have been previously described (Lucifero et al., 2002). We analysed 16 cpG sites in a 422 bp fragment of $H 19$ (GenBank acc.nr. U19619, 13041726), 16 CpG sites in a 419 bp fragment of Snrpn (AF081460, 2151-2570), $18 \mathrm{CpG}$ sites in a 286 bp fragment of Peg3 (AF105262, 2770-3056) and 7 CpG sites in a 205 bp fragment of Igf2r (L06446, 796-1001), (Lucifero et al., 2002).

For H19, Snrpn and Peg3, the first PCR reaction was performed in 50 $\mu \mathrm{L}$ and contained $2 \mu \mathrm{L}$ bisulphite-modified DNA, $5 \mu \mathrm{L}$ of $5 x$ PCR buffer II, $5 \mu \mathrm{L}$ of $2.5 \mathrm{mM} \mathrm{MgCl}{ }_{2}$ (Applied Biosystems, Nieuwerkerk, The Nether-
Fig. 5. Representative picture of the in vitro growth of an early pre-antral follicle (type $\mathbf{3 b}$ ) in defined conditions. The thecal cells attach the pre-antral follicle to the bottom of the culture dish (day1 to 4), the granulosa cells break through the basal membrane (day 4) and proliferate. The granulosa cells differentiate into a follicular wall and a cumulus-corona part (day 8). A clear antrallike cavity has formed on day 12. The hCG / EGF stimulus on these follicles provokes the release of a mucified cumulus-corona complex (day 13) surrounding a metaphase II oocyte. Note that the oocyte diameter increases from 50-55 $\mu \mathrm{m}$ (diameter in type $3 \mathrm{~b}$ follicle) up to $72-75 \mu \mathrm{m}$ (diameter before ovulation).
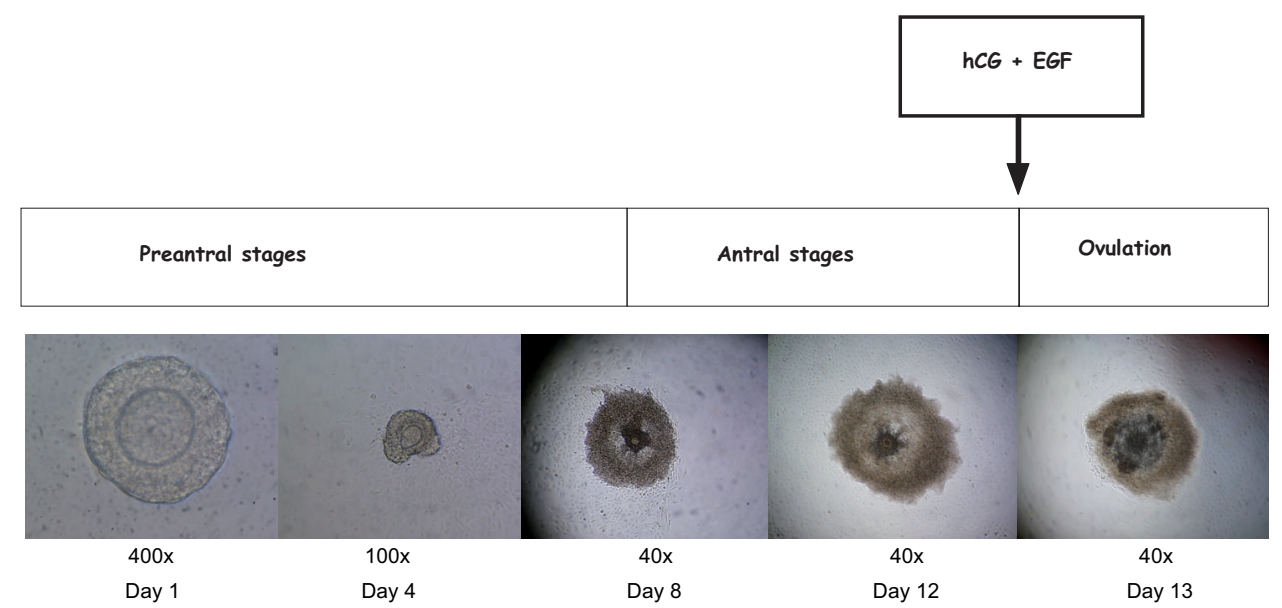
lands), $0.25 \mu \mathrm{L}$ of $2 \mathrm{mM} \mathrm{dNTPs}$ (Invitrogen), $0.5 \mathrm{n} \mu \mathrm{L}$ of $60 \mu \mathrm{M}$ for each primer solution and $0.4 \mu \mathrm{L}$ AmpliTaq (Applied Biosystems). The second PCR reaction was performed in $25 \mu \mathrm{L}$ and contained $2 \mu \mathrm{L}$ of first-round PCR product, $2.5 \mu \mathrm{L}$ of $5 \times$ PCR buffer II, $2.5 \mu \mathrm{L}$ of $2.5 \mathrm{mM} \mathrm{MgCl}_{2}, 2.5 \mu \mathrm{L}$ of $2 \mathrm{mM}$ dNTPs, $0.5 \mu \mathrm{L}$ of $60 \mu \mathrm{M}$ primer solution and $0.2 \mu \mathrm{L}$ AmpliTaq. First round PCR cycle conditions were 2 minutes at $94^{\circ} \mathrm{C}$ (pre-denaturation); 4 minutes at $94^{\circ} \mathrm{C}, 2$ minutes at $55^{\circ} \mathrm{C}$, and 2 minutes at $72^{\circ} \mathrm{C}$ for 2 cycles; 30 seconds at $94^{\circ} \mathrm{C}, 30$ seconds at $55^{\circ} \mathrm{C}$, and 30 seconds at $72^{\circ} \mathrm{C}$ for 35 cycles; 10 minutes at $72^{\circ} \mathrm{C}$ (final elongation). Second round PCR cycle conditions were similar, except for the first two cycles that were omitted.

For Igf2r, first and second round PCR was performed with the Advantage cDNA PCR Kit and Polymerase Mix (Westburg B.V., Leusden, The Netherlands) according to the instructions of the manufacturer. PCR cycle conditions were the same for first and second round PCR: 4.5 minutes at $95^{\circ} \mathrm{C}$ (pre-denaturation); 30 seconds at $95^{\circ} \mathrm{C}, 30$ seconds at $55^{\circ} \mathrm{C}$, and 30 seconds at $72^{\circ} \mathrm{C}$ for 30 cycles; 5 minutes at $72^{\circ} \mathrm{C}$ (final elongation).

\section{Cloning and sequencing}

PCR products were separated on a $1 \%$ agarose gel; bands of interest were excised and purified with the Perfectprep Gel Cleanup kit (Eppendorf AG, Hamburg, Germany). DNA was subcloned using the TOPO TA Cloning kit (Invitrogen). Plasmid DNA was isolated with the QIAprep Miniprep kit (Qiagen). For each oocyte pool, sixteen clones were sequenced per gene using M13 Reverse and M13 Forward universal primers with the Big Dye Terminator kit and the ABI PRISM 3100 sequencer (Applied Biosystems). As a control for completeness of bisulphite modification, the conversion of cytosine residus outside $\mathrm{CpG}$ s was analysed in each sequence. Cytosines outside CpGs are unmethylated and should therefore be converted by bisulphite treatment. Only sequences with $>95 \%$ bisulphite conversion of cytosine residues outside CpGs were included in the results to exclude false results due to incomplete DNA modification by bisulphite.

\section{Developmental capacity of MII oocytes after in vitro follicle culture} and in vitro maturation in the presence of 10 and $100 \mathrm{IU} / \mathrm{L} \mathrm{r-FSH}$

In vivo grown and superovulated MII oocytes and MII oocytes derived from in vitro follicle culture were used for IVF and embryo culture as described previously (Adriaens et al., 2004). Blastocysts were surgically transferred into the uterine horns of 8- to 12-week CD1, pseudopregnant females.

\section{Statistics}

For each imprinted gene, DNA methylation percentages of clones were compared in the several MII oocyte groups by Mann-Whitney $U$ analysis. For in vitro follicle cultures, MII rate and oocyte diameters were compared between the $10 \mathrm{IU} / \mathrm{L}$ and $100 \mathrm{IU} / \mathrm{L}$ r-FSH conditions by Mann-Whitney $\mathrm{U}$ analysis. Oocyte diameters were also compared between in vivo grown oocytes and both in vitro follicle culture conditions by Mann-Whitney $U$ analysis. Differences in developmental capacity (2-cell/oocyte rate, blastocyst/2-cell rate and newborn/blastocyst transfer rate) were examined between in vivo grown (and superovulated) oocytes and MII oocytes derived from in vitro follicle culture by the Chi-square test. P-values $<0.05$ were considered significant.

\section{Acknowledgements}

This work was supported by research funds from Onderzoeksraad Vrije Universiteit Brussel (OZR 1007) and Fonds voor Wetenschappelijk Onderzoek (FWO A 6/5 EP 1.7.003.08)

\section{References}

ADRIAENS, I., CORTVRINDT, R. and SMITZ, J. (2004). Differential FSH exposure in pre-antral follicle culture has marked effects on folliculogenesis and oocyte developmental competence. Hum. Reprod. 19: 398-408.

BAO, S., OBATA, Y., CARROLL, J., DOMEKI, I. and KONO, T. (2000). Epigenetic modifications necessary for normal development are established during oocyte growth in mice. Biol. Reprod. 62: 616-621.

BESTOR, T.H. (2000). The DNA methyltransferases of mammals. Hum. Mol. Genet. 9: 2395-2402.

BIELINSKA, B., BLAYDES, S., BUITING, K., YANG, T., KRAJEWSKA-WALASEK, M., HORSTHEMKE, B. and BRANNAN, C.I. (2000). De novo deletions of SNRPN exon 1 in early human and mouse embryos result in a paternal to maternal imprint switch. Nat. Genet. 25: 74-78.

BORGHOL, N., LORNAGE, J., BLACHERE, T., SOPHIE GARRET, A. and LEFEVRE, A. (2006). Epigenetic status of the H19 locus in human oocytes following in vitro maturation. Genomics 87: 417-426.

CORTVRINDT, R. and SMITZ, J. (1998). Early pre-antral mouse follicle in vitro maturation: oocyte growth, meiotic maturation and granulosa-cell proliferation. Theriogenology 49: 845-859.

CORTVRINDT, R. and SMITZ, J. (2002). Follicle culture in reproductive toxicology: a tool for in-vitro testing of ovarian function. Hum. Reprod. Update 8: 1-12.

COX, G.F., BURGER, J., LIP, V., MAU, U.A., SPERLING, K., WU B.L. and HORSTHEMKE,B. (2002). Intracytoplasmic sperm injection may increase the risk of imprinting defects. Am. J. Hum. Genet. 71: 162-164.

DAVIS, T.L., TRASLER, J.M., MOSS, S.B., YANG, G.J. and BARTOLOMEI, M.S. (1999). Acquisition of the $\mathrm{H} 19$ methylation imprint occurs differentially on the parental alleles during spermatogenesis. Genomics 58: 18-28.

DAVIS, T.L., YANG, G.J., MCCARREY, J.R. and BARTOLOMEI, M.S. (2000). The $\mathrm{H} 19$ methylation imprint is erased and re-established differentially on the parental alleles during male germ cell development. Hum. Mol. Genet. 9: 28852894.

DEBAUN, M.R., NIEMITZ, E.L. and FEINBERG, A.P. (2003). Association of in vitro fertilization with Beckwith-Wiedemann syndrome and epigenetic alterations of LIT1 and H19. Am. J. Hum. Genet. 72: 156-160.

EPPIG, J.J. and O'BRIEN, M.J. (1998). Comparison of preimplantation developmental competence after mouse oocyte growth and development in vitro and in vivo. Theriogenology. 49:415-422.

EPPIG, J.J., HOSOE, M., O'BRIEN, M.J., PENDOLA, F.M., REQUENA, A. and WATANABE, S. (2000). Conditions that affect acquisition of developmental competence by mouse oocytes in vitro: $\mathrm{FSH}$, insulin, glucose and ascorbic acid. Mol. Cell Endocrinol. 163: 109-116.

FAUQUE, P., JOUANNET, P., LESAFFRE, C., RIPOCHE, M.A., DANDOLO, L., VAIMAN, D. and JAMMES, H. (2007). Assisted Reproductive Technology affects developmental kinetics, $\mathrm{H} 19$ Imprinting Control Region methylation and $\mathrm{H} 19$ gene expression in individual mouse embryos. BMC Dev. Biol. 7: 116.

FORTIER, A.L., LOPES, F.L., DARRICARRERE, N., MARTEL, J. and TRASLER, J.M. (2008). Superovulation alters the expression of imprinted genes in the midgestation mouse placenta. Hum Mol Genet. 17: 1653-1665.

FOWDEN, A., SIBLEY, C., REIK, W. and CONSTANCIA, M. (2006). Imprinted genes, placental development and fetal growth. Horm. Res. 65 Suppl 3: 50-58.

GARDNER, D. and LANE, M. (2005). Ex vivo early embryo development and effects on gene expression and imprinting. Reprod. Fertil. Dev. 17: 361-370.

GICQUEL, C., GASTON, V., MANDELBAUM, J., SIFFROI, J.P., FLAHAULT, A. and LE BOUC, Y. (2003). In vitro fertilization may increase the risk of BeckwithWiedemann syndrome related to the abnormal imprinting of the KCN1OT gene. Am. J. Hum. Genet. 72: 1338-1341.

GRUNAU, C., CLARK, S.J. and ROSENTHAL, A. (2001). Bisulfite genomic sequencing: systematic investigation of critical experimental parameters. Nucleic Acids Res 29: E65-5.

HAJKOVA, P., ERHARDT, S., LANE, N., HAAF, T., EL-MAARRI, O., REIK, W., WALTER, J. and SURANI, M. (2002). Epigenetic reprogramming in mouse primordial germ cells. Mech. Develop. 117: 15-23.

HIURA, H., OBATA, Y., KOMIYAMA, J., SHIRAI, M. and KONO, T. (2006). Oocyte growth-dependent progression of maternal imprinting in mice. Genes Cells 11: 353-361.

HOLZER, H., SCHARF, E., CHIAN, R.C., DEMIRTAS, E., BUCKETT, W. and TAN, S.L. (2007). In vitro maturation of oocytes collected from unstimulated ovaries for oocyte donation. Fertil. Steril. 88: 62-67.

IMAMURA, T., KERJEAN, A., HEAMS, T., KUPIEC, J.J., THENEVIN, C. and PALDI, A. (2005). Dynamic CpG and non-CpG methylation of the Peg1/Mest 
gene in the mouse oocyte and preimplantation embryo. J. Biol. Chem. 280: 20171-20175.

ISLES, A. and HOLLAND, A. (2005). Imprinted genes and mother-offspring interactions. Early Hum. Dev. 81: 73-77.

KERJEAN, A., COUVERT, P., HEAMS, T., CHALAS, C., POIRIER, K., CHELLY, J., JOUANNET, P., PALDI, A. and POIROT, C. (2003). In vitro follicular growth affects oocyte imprinting establishment in mice. Eur. J. Hum. Genet. 11: 493496.

KHOSLA, S., DEAN, W., REIK, W. and FEIL, R. (2001). Culture of preimplantation embryos and its long-term effects on gene expression and phenotype. Hum. Reprod. Update 7: 419-427.

LEE, J., INOUE, K., ONO, R., OGONUKI, N., KOHDA, T., KANEKO-ISHINO, T., OGURA, A. and ISHINO, F. (2002). Erasing genomic imprinting memory in mouse clone embryos produced from day 11.5 primordial germ cells. Development 129: 1807-1817.

LI, E. (2002). Chromatin modification and epigenetic reprogramming in mammalian development. Nat. Rev. Genet. 3: 662-673.

LUCIFERO, D., MERTINEIT, C., CLARKE, H.J., BESTOR, T.H. and TRASLER, J.M. (2002). Methylation dynamics of imprinted genes in mouse germ cells. Genomics 79: 530-538.

LUCIFERO, D., MANN, M.R., BARTOLOMEI, M.S. and TRASLER, J.M. (2004). Gene-specific timing and epigenetic memory in oocyte imprinting. Hum. Mol. Genet. 13: 839-849.

MAHER, E.R., AFNAN, M. and BARRATT, C.L. (2003). Epigenetic risks related to assisted reproductive technologies: epigenetics, imprinting, ART and icebergs? Hum. Reprod. 18: 2508-2511.

MCGRATH, J. and SOLTER, D. (1984). Completion of mouse embryogenesis requires both the maternal and paternal genomes. Cell 37: 179-183.

OBATA, Y. and KONO, T. (2002). Maternal primary imprinting is established at a specific time for each gene throughout oocyte growth. J. Biol. Chem. 277: 52855289.

OHKOSHI, K., TAKAHASHI, S., KOYAMA, S., AKAGI, S., ADACHI, N., FURUSAWA, T., FUJIMOTO, J., TAKEDA, K., KUBO, M., IZAIKE, Y. and TOKUNAGA, T.
(2003). In vitro oocyte culture and somatic cell nuclear transfer used to produce a live-born cloned goat. Cloning Stem Cells 5: 109-115.

ORSTAVIK, K.H., EIKLID, K., VAN DER HAGEN, C.B., SPETALEN, S., KIERULF, K., SKJELDAL, O. and BUITING, K. (2003). Another case of imprinting defect in a girl with Angelman syndrome who was conceived by intracytoplasmic semen injection. Am. J. Hum. Genet. 72: 218-219.

PAULSEN, M. and FERGUSON-SMITH, A.C. (2001). DNA methylation in genomic imprinting, development, and disease. J. Pathol. 195: 97-110.

REIK, W. and WALTER, J. (2001). Genomic imprinting: parental influence on the genome. Nat. Rev. Genet. 2: 21-32.

SATO, A., OTSU, E., NEGISHI, H., UTSUNOMIYA, T. and ARIMA, T. (2007). Aberrant DNA methylation of imprinted loci in superovulated oocytes. Hum. Reprod. 22: 26-35.

SEGERS, I., ADRIAENSSENS, T., COUCKE, W., CORTVRINDT, R. and SMITZ, J. (2008). Timing of nuclear maturation and post-ovulatory aging in oocytes of in vitro-grown mouse follicles with or without oil overlay. Biol Reprod. 78: 859868.

SMITH, F., GARFIELD, A. and WARD, A. (2006). Regulation of growth and metabolism by imprinted genes. Cytogenet. Genome Res. 113: 279-291.

SUIKKARI, A.M. and SODERSTROM-ANTTILA, V. (2007). In-vitro maturation of eggs: is it really useful? Best Pract. Res. Clin. Obstet. Gynaecol. 21: 145-155.

SURANI, M.A., BARTON, S.C. and NORRIS, M.L. (1984). Development of reconstituted mouse eggs suggests imprinting of the genome during gametogenesis. Nature 308: 548-550.

WARNECKE, P.M., STIRZAKER, C., MELKI, J.R., MILLAR, D.S., PAUL, C.L. and CLARK, S.J. (1997). Detection and measurement of PCR bias in quantitative methylation analysis of bisulphite-treated DNA. Nucleic Acids Res. 25: 44224426.

YOUNG, L.E., FERNANDEZ, K., MCEVOY, T.G., BUTTERWITH, S.C., GUTIERREZ, C.G., CAROLAN, C., BROADBENT, P.J., ROBINSON, J.J., WILMUT, I. and SINCLAIR, K.D. (2001). Epigenetic change in IGF2R is associated with fetal overgrowth after sheep embryo culture. Nat. Genet. 27: 153-154. 


\section{Further Related Reading, published previously in the Int. J. Dev. Biol.}

See our recent Special Issue Fertilization, in honor of David L. Garbers and edited by Paul M. Wassarman and Victor D. Vacquier at: http://www.ijdb.ehu.es/web/contents.php?vol=52\&issue=5-6

Imprinting of mammalian male gametes is gene specific and does not occur at a single stage of differentiation María D. Boyano, Noelia Andollo, María M. Zalduendo and Juan Aréchaga

Int. J. Dev. Biol. (2008) 52: 1105-1111

Animal reproduction biotechnology in Poland

Zdzislaw Smorag, Lucyna Katska-Ksiazkiewicz, Maria Skrzyszowska, Jacek Jura, Barbara Gajda and Michal Bochenek Int. J. Dev. Biol. (2008) 52: 151-155

Hypomethylation of paternal DNA in the late mouse zygote is not essential for development Zbigniew Polanski, Nami Motosugi, Chizuko Tsurumi, Takashi Hiiragi and Steffen Hoffmann Int. J. Dev. Biol. (2008) 52: 295-298

DNA methylation state is preserved in the sperm-derived pronucleus of the pig zygote Young-Sun Jeong, Seungeun Yeo, Jung-Sun Park, Deog-Bon Koo, Won-Kyung Chang, Kyung-Kwang Lee and Yong-Kook Kang Int. J. Dev. Biol. (2007) 51: 707-714

Control of reproduction by Polycomb Group complexes in animals and plants Anne-Elisabeth Guitton and Frederic Berger Int. J. Dev. Biol. (2005) 49: 707-716

An intense half-semester developmental biology course, as taught at Uppsala University, Sweden. Lennart Olsson Int. J. Dev. Biol. (2003) 47: 171-176

KL/KIT co-expression in mouse fetal oocytes.

Luisa Doneda, Francesca-Gioia Klinger, Lidia Larizza and Massimo De Felici Int. J. Dev. Biol. (2002) 46: 1015-1021

Methylation and chromatin conformation in the U2af1-rs1 imprinted gene in the male germ cell line MM Zalduendo, D Boyano, R Feil, N Andollo, J Arechaga Int. J. Dev. Biol. (2001) 45: S145-S146

Epigenetic reprogramming of the genome-from the germ line to the embryo and back again.

K L Arney, S Erhardt, R A Drewell and M A Surani Int. J. Dev. Biol. (2001) 45: 533-540

Of microbes, mice and man.

M Monk

Int. J. Dev. Biol. (2001) 45: 497-507

A history of mammalian embryological research.

$\mathrm{H}$ Alexandre

Int. J. Dev. Biol. (2001) 45: 457-467

Igf2 imprinting in development and disease.

W Reik, M Constancia, W Dean, K Davies, L Bowden, A Murrell, R Feil, J Walter and G Kelsey

Int. J. Dev. Biol. (2000) 44: 145-150

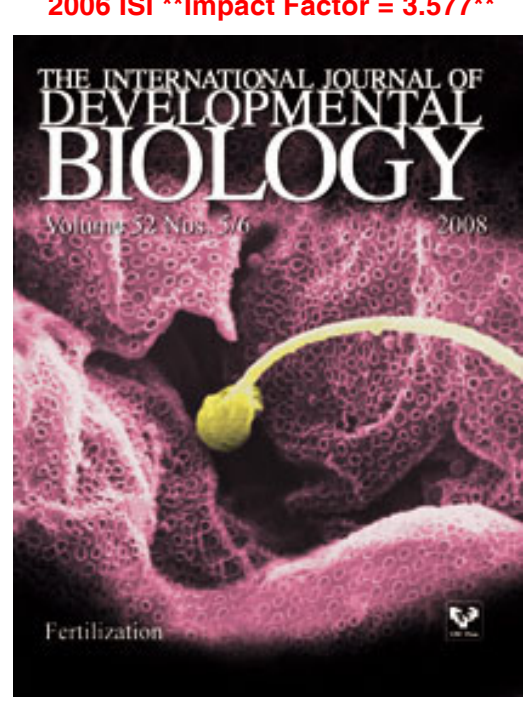

